\title{
Sequential Contraction Compression Device Therapy affects Symptomatic Diabetic Peripheral Neuropathy
}

\section{Jonathan Rosenblum $^{1 *}$, Leib Litman ${ }^{2}$ and Nachum Greenberg ${ }^{3}$}

${ }^{1}$ Diabetic Foot Service, Israel

${ }^{2}$ Lander College, New York, USA

${ }^{3}$ Shaarei Zedek Medical Center, Jerusalem, Israel

*Corresponding author: Jonathan Rosenblum, Director, Diabetic Foot Service, Israel, Tel: +972-50-595-5161; E-mail: diabfootman@gmail.com

Received date: Jul 24, 2016; Accepted date: Aug 12, 2016; Published date: Aug 18, 2016

Copyright: (c) 2016 Rosenblum J et al. This is an open-access article distributed under the terms of the Creative Commons Attribution License, which permits unrestricted use, distribution, and reproduction in any medium, provided the original author and source are credited.

\begin{abstract}
The authors evaluate a novel compression device, Sequential Contraction Compression Therapy Device (SCCD) on patients with hypo esthetic Diabetic Peripheral Neuropathy. The authors selected 15 patients all of whom had a diagnosis of DPN and were currently taking $150 \mathrm{mg}$. of Pregabalin twice daily. After thirty days of treatment with SCCD, patients were evaluated for improvement in their pain score, amount of rescue drugs used, and the amount of sleep interference they experienced. All patients experience statistically significant improvement in all three measurements.
\end{abstract}

Keywords: Diabetic peripheral neuropathy; Compression therapy; Diabetes; Muscle stimulation

\section{Introduction}

Diabetic Peripheral Neuropathy is a chronic, symmetrical, lengthdependent sensorimotor polyneuropathy (DSPN) and is thought to be most commonly divided into hyperesthetic DPN and hypoesthetic DPN [1]. DPN develops from a background of long-standing hyperglycemia, associated metabolic derangements oxidative stress, and lipid alterations and cardiovascular risk factors [2,3]. A newer hypothesis for a contributing factor to DPN is the alteration of microvessels, similar to those observed in diabetic retinopathy and nephropathy, affecting the nerves $[4,5]$.

It has been reported in the literature that between 3 and $25 \%$ of patients with DPN will have neuropathic pain [6]. The symptoms include distal, symmetrical, exacerbated nocturnally, and commonly described as prickling, deep aching, sharp, like an electric shock, and burning with hyperalgesia and frequently allodynia upon examination [7].

Pharmacological management of painful DPN almost exclusively consists of symptomatic therapies [8]. These drugs are often associated with side effects including somnolence, dizziness, nausea and compliance is mixed.

Sequential contraction compression device (SCCD) therapy has shown effectiveness in treating circulatory disorders of the lower extremities [9]. The method of action of the SCCD is to increase venous outflow from the limb by a series of peristaltic contractions of the calf muscles. The resultant change in the AV gradient causes an increased inflow to the limb [10].

The new understanding that DPN is also microvascular disease would predict an indication for treatment of DPN with circulatory enhancers. The authors evaluate a sequential contraction compression device (SCCD), the Flowaid FA-100 (Flowaid Medical Technology
Corp. New York, USA) for the treatment of painful diabetic peripheral neuropathy.

\section{Materials and Methods}

15 patients were enrolled in the study. Table 1 demonstrates the demographic distribution of the study subjects.

\begin{tabular}{|c|c|c|c|}
\hline Patient Number & Age & Gender & $\begin{array}{l}\text { Duration of Condition } \\
\text { (years) }\end{array}$ \\
\hline 1 & 64 & $M$ & 1.5 \\
\hline 2 & 57 & $\mathrm{~F}$ & 4 \\
\hline 3 & 63 & $\mathrm{~F}$ & 3 \\
\hline 4 & 68 & $M$ & 1 \\
\hline 5 & 72 & $M$ & 7 \\
\hline 6 & 54 & $M$ & 5 \\
\hline 7 & 56 & $\mathrm{~F}$ & 4 \\
\hline 8 & 67 & $M$ & 3 \\
\hline 9 & 62 & M & 3 \\
\hline 10 & 70 & $\mathrm{~F}$ & 4 \\
\hline 11 & 69 & $M$ & 3 \\
\hline 12 & 58 & $\mathrm{~F}$ & 4 \\
\hline 13 & 49 & $M$ & 4 \\
\hline 14 & 57 & $M$ & 5 \\
\hline 15 & 47 & $\mathrm{~F}$ & 5 \\
\hline
\end{tabular}

Table 1: Demographic Data of Subjects 
Page 2 of 3

All 15 had a diagnosis, confirmed by Nerve Conduction Velocity (NCV) of Diabetic Peripheral Neuropathy that was not complicated by a more central lesion such as radiculopathy or nerve root inflammation. All 15 were symptomatic with pain, burning, and awakening at least almost every night for a minimum of 6 months. All 15 were currently taking Pregabalin $150 \mathrm{mg}$. bid for at least 30 days with no relief from their symptoms. All had also tried at a minimum at least one course of Cymbalta prior to being switched to Pregabalin.

Upon enrolment, subjects were asked to complete a questionnaire, which included a Visual Analog Scale (VAS) pain scoring, a record of how much rescue analgesics they were taking beyond the Pregabalin prescription in an average 24 hour period, and a record of how many times they were awakened from their sleep on the average night. Patients also underwent a baseline NCV.

Subjects were given a Flowaid FA-100 (Flowaid Medical Technologies Corp. New York, USA) Sequential Contraction
Compression Device (SCCD) to use at home for two hours per leg once daily. The SCCD was set to the PA setting. Patients were monitored for compliance by daily phone calls from a study assistant.

After 30 days of treatment with the SCCD subjects returned for reevaluation and completed the same questionnaire they did at intake, as well as undergoing a follow up NCV.

The study was approved by an IRB before any patients were enrolled, and patients signed an informed consent at the beginning of the study procedure.

\section{Results}

Table 2 summarizes the results of the study. All patients showed a positive reaction to treatment with SCCD in all three measured parameters.

\begin{tabular}{|c|c|c|c|c|c|c|}
\hline Patient Number & VAS Pre-Study & $\begin{array}{l}\text { VAS at } 30 \\
\text { days }\end{array}$ & $\begin{array}{l}\text { Rescue Drug } \\
\text { Usage Pre Study }\end{array}$ & $\begin{array}{l}\text { Rescue Drug } \\
\text { Usage at } 30 \text { days }\end{array}$ & $\begin{array}{l}\text { Times } \\
\text { Study }\end{array}$ Awakened Pre & $\begin{array}{l}\text { Times Awakened at } 30 \\
\text { Days }\end{array}$ \\
\hline 1 & 8 & 4 & 4 & 1 & 3 & 0 \\
\hline 2 & 7 & 4 & 3 & 1 & 4 & 1 \\
\hline 3 & 7 & 3 & 3 & 0 & 3 & 0 \\
\hline 4 & 9 & 4 & 4 & 0 & 4 & 0 \\
\hline 5 & 8 & 2 & 3 & 1 & 3 & 1 \\
\hline 6 & 6 & 2 & 3 & 0 & 3 & 0 \\
\hline 7 & 7 & 3 & 2 & 0 & 3 & 0 \\
\hline 8 & 7 & 3 & 4 & 1 & 4 & 1 \\
\hline 9 & 7 & 2 & 3 & 1 & 4 & 0 \\
\hline 10 & 8 & 4 & 4 & 0 & 3 & 1 \\
\hline 11 & 8 & 3 & 3 & 0 & 2 & 0 \\
\hline 12 & 9 & 4 & 5 & 1 & 3 & 1 \\
\hline 13 & 8 & 3 & 3 & 1 & 3 & 1 \\
\hline 14 & 7 & 3 & 2 & 0 & 3 & 0 \\
\hline 15 & 6 & 2 & 2 & 0 & 2 & 0 \\
\hline
\end{tabular}

Table 2: Summary of the Results of the Study

Paired-samples t-tests were utilized to compare pre-drug treatment scores to post-treatment scores for three outcomes: VAS, rescue drug usage, and times awakened. The t-tests showed that there were significant improvements for each of the outcomes. The average VAS improvement was 4.4 (pre-treatment mean=7.5, post-treatment mean=3.1), $\mathrm{t}(14)=23.1, \mathrm{p}<.001)$. The average rescue drug usage improvement was 2.7 (pre-treatment mean $=3.2$, post-treatment mean=0.47), $\mathrm{t}(14)=13.2, \mathrm{p}<.001)$. The average improvement in times awakened was 2.7 (pre-treatment mean $=3.1$, post-treatment mean $=0.4), \mathrm{t}(14)=15, \mathrm{p}<.001)$.

12 of the 15 patients related significant improvement in the first week.
NCV studies showed a trending toward improvement but the results were not significant.

\section{Discussion}

While traditionally DPN was thought to be a metabolic disease, newer research shows that micro ischemia, and pathologic alterations of the micro vessels play an important role in the progression of the disease $[1,11]$. The authors have previous experience with the SCCD and have seen its effect on distal blood flow in the lower extremities $[9,10]$. The authors have also seen prior to this study anecdotal evidence of a positive effect of SCCD on symptomatic painful DPN. 
Because this was the first study of SCCD for the treatment of painful DPN, it was kept to an open label observational study. While the limitations of such a study are known, the inclusion criteria were carefully monitored and based on the recommendations of the Diabetic Neuropathy Study group [12]. These included NP associated with DPN for $>6$ months duration, mean weekly pain score of between 4 and 10 on an 11-point numerical rating scale, exclusion of pain not associated with DPN, mononeuropathies or proximal neuropathies, non-neuropathic chronic pain, and central pain.

Evaluation of subjects was also done in line with recommendations of the Study group as well as based on the construct of previously published literature of other modalities for the treatment of DPN. The study group states that the severity of pain can be reliably assessed by the visual analog scale, which is the oldest and best validated measure, or the numerical rating scale, e.g., the 11 -point Likert scale $(0=$ no pain, $10=$ worst possible pain). They also state that external observers can play no part in the assessment of the subjects' responses to new therapies for NP; thus, measures such as the "physician's global impression of response" are not valid.

SCCD compared well with results reported for Pregabalin effect on neuropathic pain which ranged from $11 \%-13 \%[13,14]$. It also compared well with regard to sleep interference $[15,16]$.

Because SCCD is a mechanical modality and there is no drug usage, no drug- drug interacting or pharmacological side effects are observed.

The authors hypothesize that by hyperperfusing the limb, excess arterial pressure is shifted into the microvasculature where it is then able to regenerate hypoxic and ischemic nerve tissue.

Neuroregeneration would have an effect on objective examinations such as NCV, but it is expected that these results would lag, perhaps even significantly behind the subjective results.

This study was limited by the sample size which was small and did not lend itself to a full statistical evaluation of the subject's results. In addition, the duration of the observation lent itself to a good evaluation of subjective data but did not allow for objective results to occur. Lastly, the open label nature of the study, did not give a full picture of the efficacy of the study device. Only through an randomized controlled trial could these things be properly evaluated. Further research should include a larger sample size, with a sham or placebo controlled arm. It should follow subjects for longer to give enough time for NCV results to occur. Other tests such as nerve fiber density evaluation should also be considered.

\section{Conclusion}

SCCD shows effectiveness in treating painful DPN. While the results of this study were significant, a larger scale, randomized clinical trial is indicated. It is also suggested that any such trial document the progression of subjective results more frequently, follow for a longer time to evaluate for objective findings as well. The newer understanding of the micro ischemic nature of DPN and the results shown in studies such as this one could alter the way DPN is treated.

\section{References}

1. Dyck PJ, Kratz KM, Karnes JL, Litchy WJ, Klein R, et al. (1993) The prevalence by staged severity of various types of diabetic neuropathy, retinopathy, and nephropathy in a population-based cohort: the Rochester Diabetic Neuropathy Study. Neurology 43: 817-824.

2. Tesfaye S, Chaturvedi N, Eaton SE, Ward JD, Manes C, et al. (2005) EURODIAB Prospective Complications Study Group Vascular risk factors and diabetic neuropathy. N Engl J Med 352: 341-350

3. Dyck PJ, Davies JL, Wilson DM, Service FJ, Melton LJ, et al. (1999) Risk factors for severity of diabetic polyneuropathy: intensive longitudinal assessment of the Rochester Diabetic Neuropathy Study cohort. Diabetes Care 22: 1479-1486.

4. Giannini C, Dyck PJ (1994) Ultrastructural morphometric abnormalities of sural nerve endoneurial microvessels in diabetes mellitus. Ann Neurol 36: 408-415.

5. Dyck PJ, Davies JL, Clark VM, Litchy WJ, Klein CJ, et al. (2006) Modeling chronic glycemic exposure variables as correlates and predictors of microvascular complications of diabetes. Diabetes Care 29: 2282-2288.

6. Boulton AJ, Malik RA, Arezzo JC, Sosenko JM (2004) Diabetic somatic neuropathies. Diabetes Care 27: 1458-1486.

7. Apfel SC, Asbury AK, Bril V, Burns TM, Campbell JN, et al. (2001) Ad Hoc Panel on Endpoints for Diabetic Neuropathy Trials Positive neuropathic sensory symptoms as endpoints in diabetic neuropathy trials. J Neurol Sci 189: 3-5.

8. Tesfaye S (2009) Advances in the management of diabetic peripheral neuropathy. Curr Opin Support Palliat Care 3: 136-143.

9. Rosenblum J, Gimmelreich D, Greenberg N (2016) Sequential Contraction Compression has a Positive Effect on Patients with Peripheral Arterial Disease. Journal of Novel Physiotherapies 6: 3.

10. Shashar D, Rosenblum J, Miller M, Heidinberg E, Tamir J (2016) An Evaluation of a Novel Compression Device on Popliteal Venous Blood Flow. Angiology Open Access 4: 2.

11. Dyck PJ, Giannini C (1996) Pathologic alterations in the diabetic neuropathies of humans: a review. J Neuropathol Exp Neurol 55: 1181-1193.

12. Tesfaye S, Boulton AJM, Dyck PJ, Freeman R, Horowitz M, et al. (2010) Diabetic Neuropathies: Update on Definitions, Diagnostic Criteria, Estimation of Severity, and Treatments. Diabetes Care 33: 2285-2293.

13. Lesser H, Sharma U, LaMoreaux L, Poole RM (2004) Pregabalin relieves symptoms of painful diabetic neuropathy: a randomized controlled trial. Neurology 63: 2104-2110.

14. Rosenstock J, Tuchman M, LaMoreaux L, Sharma U (2004) Pregabalin for the treatment of painful diabetic peripheral neuropathy: a double-blind, placebo-controlled trial. Pain 110: 628-638.

15. Freeman R, Decruz ED, Emir B (2008) Efficacy, safety, and tolerability of pregabalin treatment for painful diabetic peripheral neuropathy: findings from seven randomized, controlled trials across a range of doses. Diabetes Care 31: 1448-1454.

16. Vinik A, Zlateva G, Cheung R, Murphy K, Emir B, et al. (2010) Understanding the impact of pain response on changes in function, quality of life, and sleep interference in patients with painful diabetic peripheral neuropathy and post-herpetic neuralgia treated with pregabalin. J Pain 11: S17. 